of the Academy was Prince Leopold de' Medici, brother of Grand Duke Ferdinand of Tuscany. As Dr Middleton shows, Ferdinand was also artively interested in both scientific experiment and these particular experimenters. The experimenters themselves (not named in the Saggi) were eight. Of these only Borelli, Redi and Viviani are generally known today, although Carlo Rinaldini had a considerable reputation among his contemporaries. Redi seems not to have been very active and most of the effective experiments were devised by Borelli and Viviani, although Prince Leopold was energetic in designing experiments on freezinga subject of perpetual fascination to Italians. One of Borelli's most interesting experiments-one that unfortunately did not appear in the Saggiwas a study of Saturn, in which a physical model was made of Saturn's ring as postulated by Huygens, which was viewed under various conditions by both trained and untrained observers to see whether the observed celestial phenomena could be repeated.

Dr Middleton has written an extremely thorough and scholarly study, based on the work of the eighteenth century scholar Giovanni Targioni Tozzetti and the original archives. He has described the sources, discussed the composition and functioning of the Academy and the biographies of its members, translated anew and annotated the Saggi, described unpublished experiments, the dissolution of the Academy, and its relations abroad. There is a great deal of information here.

Marie BoAs Hall

\section{Reactions with Proteins}

Chemical Modification of Proteins. By Gary E. Means and Robert E. Feeney. Pp. $\mathbf{x}+254$. (Holden Day: San Francisco and London, October 1971.) $\$ 13.50$ cloth; $\$ 7.50$ paperback.

Ir is most unfortunate for authors writing on protein chemistry and its applications that their work will inevitably be compared with Hirs's excellent and comprehensive treatise, Methods in Enzymology, volume 11. I can give no stronger recommendation than that this much smaller book stands up well to the comparison.

The division into two main sections is effective and the cross-referencing between them good. In the first part-a general discussion on why chemical modifications are important-it is very comforting to see Hammett plots presented and the relationship of reactivity to $p \mathbf{K}_{a}$ and environment stressed. This exposes the "black magic" approach that is often adopted in this field and the dangerous phrase "specifically re- active" is refreshingly absent. This part ends with a chapter on the potential problems encountered. It will be very useful to research workers new to the field and students alike. The second part contains a detailed description of both the common and the unusual reagents used. Potential side reactions and the properties of the derivatives are discussed, together with techniques for estimating the extent of reaction. It is both comprehensive and readable-a combination not always found.

A small appendix describing a few experiments abstracted directly from the literature seems a little out of place. Research workers will surely read the original papers themselves, while others, student or non-specialist, do not require this degree of practical detail. The bibliography is extensive and there are many excellent tables that are individually referenced, which is a great convenience. Table 1-1 will be a boon to students: Unfortunately it contains an error, corrected in the text, stating that the reaction of maleic anhydride with sulphydryl groups is reversible. This does not significantly detract from my feeling that this is a first-class book and that the paperback version at $£ 2.95$ makes Hirs's pandect at $£ 15.40$ seem rather an expensive luxury.

\section{J. BRuton}

\section{Planetary Exploration}

Geological Problems in Lunar and Planetary Research. Edited by Jack Green. Pp. xiv + 736. (AAS Publications: Tarzana California, 1971.)

THIs is an unusual book. It is a collection of papers, which in itself does not make it unusual these days except that it includes papers from not one but three symposia in the field of "extraterrestrial geology" (an etymologically incorrect term but $I$ think it is clear what I mean). But then not all the papers from the three symposia are there; the editor has done a pruning job to his satisfaction and included only a select few and then, for good measure, added a few others which had not been presented at any of the symposia but are relevant because they deal with the returned samples from the Apollo 11 and 12 missions, while the symposia took place (two in 1968 and one in 1969) before man's landing on the Moon. All this makes the volume dated in a sense; but much of the matarial deals not with an attempt at a grand reconstruction of lunar (or other planetary) history but with defining potential research problems related mainly to the Moon, but also to other planets as well, and with discussing the various exploration techniques. The symposia took place when the severe cuts in the Apollo budget had not become a reality and one could look beyond Apollo 17 (now scheduled for December 10, 1972) to other future missions, up to a projected Apollo 20. Thus, although those papers which discuss bigger and better lunar rovers, or very deep drilling projects on the Moon seem, with hindsight, to be mere wishful thinking on the part of the aerospace engineers, there are other papers which present clearly the physical principles and limitations of remote sensing techniques or photogeology, the value of which has not been affected by the vagaries of Washington, DC.

The second unusual character of this volume is the style of some of the papers. They seem to be verbatim records of the symposia (including both papers and discussions thereof) and I get the impression that they must have been rather lively in character. One example is the paper by N. M. Short defending the impact theory of lunar morphology and its discussion (or dissection?) by editor Jack Green, a propounder of the volcanic theory. Unlike the recent Houston conference proceedings dealing with returned lunar samples, the present collection of papers is aimed at the broad scientific and engineering community. In fact, it resembles a sort of hand-out material which would excellently suit science reporters for national newspapers. There are five sections in the book: sensing techniques, phenomenology, exploration concepts, exploration methods and technology and, finally, "general subjects". Under this last heading one finds a mixed bag that violently refuses to be classified under any of the previous headings but contains three interesting papers, one on water management on Earth, one attacking the plethora of melliffuous but etymologically incorrect terms (e.g., geocosmo$\operatorname{logy}$, lunar geology, astrogeology and, of course, extra-terrestrial geology) and a final one on lunar "colonization"!

So, if you want to disregard the writing on the NASA wall and would like to have a middle-brow description of planetary exploration problems, go ahead and get a copy of this book. And why not? The best thing about this book is that it is free.

Subir BanerJee

\section{Adapting to Altitude}

High Altitude Physiology: Cardiac and Respiratory Aspects. A Ciba Foundatiun Symposium. Edited by Ruth Porter and Julie Knight. Pp. xi+196. (Churchill Livingstone: Edinburgh and London, 1971.) $£ 3$.

NEARLY fifty years ago Haldane, Douglas and Fitzgerald performed their classic studies of the changes seen when 